\title{
Phytophthora Brown Rot of Citrus: Temperature and Moisture Effects on Infection, Sporangium Production, and Dispersal
}

\author{
L. W. Timmer, Professor, and S. E. Zitko, Senior Biologist, University of Florida, Citrus Research and Education \\ Center, Lake Alfred 33850; T. R. Gottwald, Research Plant Pathologist, USDA, ARS, Orlando, FL 32803; and \\ J. H. Graham, Professor, University of Florida, Citrus Research and Education Center, Lake Alfred 33850
}

\begin{abstract}
Timmer, L. W., Zitko, S. E., Gottwald, T. R., and Graham, J. H. 2000. Phytophthora brown rot of citrus: Temperature and moisture effects on infection, sporangium production, and dispersal. Plant Dis. 84:157-163.

Sporadic epidemics of Phytophthora brown rot occur in citrus orchards in Florida and are caused primarily by Phytophthora palmivora and secondarily by P. nicotianae. With P. palmivora, fruit wetness durations of $3 \mathrm{~h}$ or more resulted in maximum infection at favorable temperatures. The optimum temperature range for fruit infection and brown rot development was 27 to $30^{\circ} \mathrm{C}$. No brown rot developed at $22^{\circ} \mathrm{C}$ or less. The optimum temperature for sporulation in culture and on the fruit surface was $24^{\circ} \mathrm{C}$, with sporangium production decreasing rapidly at higher or lower temperatures. A few sporangia were produced with $18 \mathrm{~h}$ of fruit wetness, and numbers increased as duration of wetness increased up to $72 \mathrm{~h}$. Propagules were splash-dispersed by single droplets of water from infested peel disks horizontally about 350 to $450 \mathrm{~mm}$ and vertically about 30 to $45 \mathrm{~mm}$ with most isolates. Sporangia were not dispersed by air currents alone. Few sporangia of $P$. nicotianae were produced on fruit surfaces, and they were not readily dispersed by falling water droplets. Brown rot caused by $P$. palmivora can become epidemic in Florida from July to October during the rainy season because of its high temperature optimum and prolific sporulation on the fruit surface.
\end{abstract}

Additional keywords: splash dispersal

Occasional epidemics of Phytophthora brown rot of citrus fruit in Florida have been reported since the 1950s $(2,19,20)$. The Phytophthora sp. involved in most of the early outbreaks was not determined. $P$. nicotianae Breda de Haan (=P. parasitica Dastur) is the most common species causing foot rot and root rot of citrus in Florida and can occasionally be recovered from brown rot-affected fruit $(7,18)$. Whiteside (20) identified the causal agent of brown rot in the 1960 s as P. citrophthora (R.E. Sm. \& E.H. Sm.) Leonian. He attributed the sporadic occurrence of brown rot to the restricted distribution of $P$. citrophthora and the lack of favorable conditions for epidemics during most years.

The causal agent in recent outbreaks of brown rot of citrus in Florida has been identified as P. palmivora (E.J. Butler) E.J. Butler $(8,9)$. This species was first recov-

Corresponding author: L. W. Timmer

E-mail: lwt@lal.ufl.edu

Current address of S. E. Zitko: American Cyanamid Co., Princeton, NJ 08543-0400.

Florida Agricultural Experiment Station Journal Series R-07082.

Accepted for publication 20 October 1999.

Publication no. D-1999-1122-01R

(c) 2000 The American Phytopathological Society ered from soil samples in groves on Florida's east coast (21). It proved highly pathogenic to roots, stems, and fruit, but has been most commonly associated with Phytophthora brown rot of fruit $(8,9)$. Populations of $P$. palmivora do not usually remain at high levels in the soil (9). It appears that in the field, $P$. palmivora is baited from the soil by fallen fruit. Sporangia are then produced on those fruit and are dispersed throughout the tree, where they infect the fruit.

The conditions for infection, sporangium production, and dispersal of $P$. palmivora on citrus have not been investigated. Of the other Phytophthora fruit rot diseases, leather rot of strawberry, caused by $P$. cactorum, has been the most extensively studied $(11,13,15)$. In that pathosystem, $100 \%$ infection occurred with only $3 \mathrm{~h}$ of fruit wetness at 18 to $24^{\circ} \mathrm{C}$. Maximum sporangium production on strawberry fruit required at least $24 \mathrm{~h}$ of wetness (13). Streams of water droplets falling on sporangia laden fruit were able to disperse sporangia up to $0.1 \mathrm{~m}$ from affected fruit (11). With P. cactorum on apples and pears, infection required 3 to $7 \mathrm{~h}$ of wetness at temperatures of 15 to $30^{\circ} \mathrm{C}$ (12). With fruit rot of papaya caused by $P$. palmivora, infection occurs very rapidly at optimum temperature (3). Sporangia produced by $P$. palmivora on papaya were not dispersed by wind in the absence of rainfall (14). Rain splash served as an effective means of dispersal, with the larger droplets containing most of the sporangia.

The purpose of the current study was to determine the temperature and moisture conditions favoring infection and sporangium production, and the means and distance of dispersal of $P$. palmivora and $P$. nicotianae attacking citrus fruit.

\section{MATERIALS AND METHODS}

Isolates. The $P$. nicotianae isolates used in this study, BLTN and BHG7, were isolated from soils in citrus nurseries near Tavares in 1987 and near Frostproof in 1991, respectively. The SH-I and Plt B and $\mathrm{C}$ isolates of $P$. palmivora were isolated from orchard soils near Ft. Pierce in 1988 and 1989, respectively. All other isolates of $P$. palmivora were from fruit: EB-1 from G. E. Brown, Department of Citrus, Lake Alfred, 1988; Sim from Mims, Florida, 1989; and Frd 1 and Frd 2 from Indiantown, Florida, 1992.

Effect of temperature and duration of wetness on infection of fruit and development of brown rot. Zoospores of isolate Plt B of $P$. palmivora were produced by first growing mycelium in clarified V8 (CV8) broth (14) for 2 days at $27^{\circ} \mathrm{C}$ (16). Mycelial mats were then washed three times in sterile distilled water and incubated in sterile distilled water in the dark at $27^{\circ} \mathrm{C}$ for sporangium production. Cultures were chilled for $15 \mathrm{~min}$ at $4^{\circ} \mathrm{C}$ and returned to $27^{\circ} \mathrm{C}$ to induce zoospore formation.

For fruit inoculations, mature Hamlin oranges were harvested, washed, and surface-disinfested by wiping with $70 \%$ ethanol. Ten fruit were then placed in closed plastic humid chambers supported on wire mesh stands above water reservoirs to achieve near $100 \%$ relative humidity (RH). Three replicate humid chambers, each containing 10 fruit, were used for each temperature-time combination. Two droplets of inoculum, each containing about $10^{5}$ zoospores per $\mathrm{ml}$, were placed on the surface of each fruit, and the chambers were immediately closed.

In the first two experiments, fruit was incubated at $24,27,30$, or $33^{\circ} \mathrm{C}$ for moist periods of $3,6,9$, or $12 \mathrm{~h}$. In the third experiment, fruit was incubated at $18,22,27$, or $30^{\circ} \mathrm{C}$ for 3,6 , or $9 \mathrm{~h}$. In a fourth experiment, time was not included as a factor, and a moist period of $6 \mathrm{~h}$ was used for temperatures of $17,20,24,27$, and $30^{\circ} \mathrm{C}$. 
After the assigned moist periods, droplets were removed using filter paper. Microscopic examination indicated that zoospores encysted very quickly and cysts were not removed with the water droplets. The lids of the chambers were removed to allow the fruit to dry and then replaced after the fruit surface had dried. After 1 week, the proportion of fruit developing any brown rot symptoms (disease incidence) was determined. The proportion of surface area of the fruit affected (disease severity) was estimated for each fruit.

Data were subjected to analysis of variance using the "Mixed" option in SAS (Version 6.12, SAS Institute, Cary, NC). An incomplete block design was used, considering experiments as blocks. Temperature and wetness duration, where used, were considered fixed factors, and experiment was considered a random factor. The experiments were analyzed as split plots with temperature as the main plot and wetness duration as the subplot.

Sporangium production in vitro. Seven isolates of $P$. palmivora were grown on CV8 agar plates for 4 days at $27^{\circ} \mathrm{C}$. Agar plugs from the margin of the colony, $3.5 \mathrm{~mm}$ in diameter, were cut using a cork borer and transferred to three replicate petri dishes for each temperature-isolate combination. Cultures were incubated at $27^{\circ} \mathrm{C}$ for $24 \mathrm{~h}$ in $\mathrm{CV} 8$ broth, then the mycelial mats were washed three times in sterile distilled water and transferred to incubators with a 12-h photoperiod using cool-white fluorescent lamps. Five experiments were conducted: the first three using temperatures of $20,24,27,30$, and $33^{\circ} \mathrm{C}$ and the other two using temperatures of 17 , $20,24,27$, and $30^{\circ} \mathrm{C}$. After incubation for $48 \mathrm{~h}$, each mycelial mat was transferred to a test tube with $10 \mathrm{ml}$ of water, vortexed for $30 \mathrm{~s}$, and the number of sporangia in the suspension determined using a hemacytometer. Data were expressed as the number of sporangia per mycelial mat.

Data were transformed using $\log _{10}(x+$ 1 ), where $x=$ number of sporangia per mycelial mat, and subjected to analysis of variance using the Mixed option in SAS Version 6.12. An incomplete block design was used, considering experiments as blocks. Isolate and temperature were considered fixed factors, and experiment was considered a random factor.

Sporangium production on fruit by isolates of $P$. palmivora and $P$. nicotianae. Mature Hamlin orange fruit (10 to 15 per isolate) were inoculated with zoospores of isolates Sim, Plt C, and Sh-I of P. palmivora and isolates BHG-7 and BLTN of $P$.

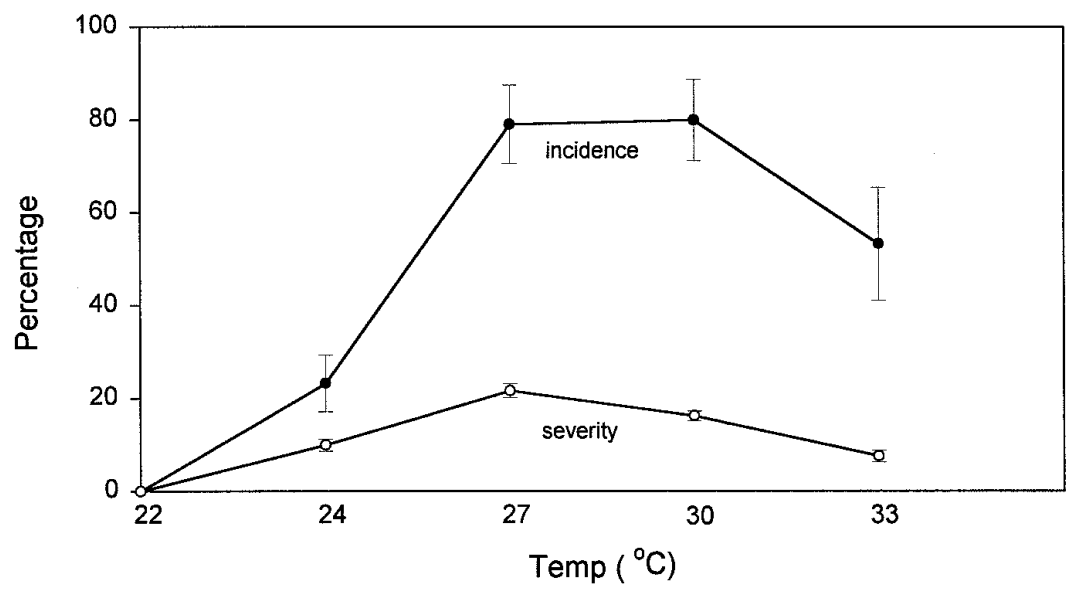

Fig. 1. Effect of temperature on incidence and percentage of the surface area (severity) affected by brown rot caused by Phytophthora palmivora. Bars represent the standard error of the mean. nicotianae and placed in humid chambers as described above. Inoculated fruit were incubated at 21 to $24^{\circ} \mathrm{C}$ in the laboratory for 1 week. Sporangium production was estimated by removing one 9 -mm-diameter disk from the peel within the rotted area of each fruit. The disk was placed in $1.0 \mathrm{ml}$ of water, vortexed for $30 \mathrm{~s}$, and the sporangia in the suspension counted using a hemacytometer. Data were expressed as the number of sporangia per $\mathrm{cm}^{2}$ of fruit surface. Three experiments were conducted, and since there were no significant isolateexperiment interactions, the data were pooled for analysis. Data were transformed using $\log _{10}(x+1)$, where $x=$ number of sporangia per $\mathrm{cm}^{2}$ of fruit surface area, and subjected to analysis of variance using the GLM procedure of SAS Version 6.12 to determine if significant differences existed between species or among isolates within a species.

Effect of temperature and fruit wetness duration on sporangium production on fruit. Fruit with brown rot symptoms were produced as described above. Fruit with 50 to $75 \%$ of the surface area affected by brown rot were washed with soap and water to remove surface mycelium and other structures and air-dried. Fruit were then sprayed using a hand-pump sprayer with distilled water to moisten the surface and placed on wire racks in humid chambers as described above. Fruit were incubated at $17,20,24,27$, and $30^{\circ} \mathrm{C}$ with a 12-h photoperiod using cool-white fluorescent lamps and fruit wetness durations of $18,24,36$, and 48 h. Five single-fruit replicates were used for each temperaturemoist period combination. Sporangium production was measured by removing five 1-cm-diameter peel disks from each fruit with a cork borer. Sporangia were scraped from the peel disks into $5 \mathrm{ml}$ of distilled water, and the tubes were vortexed. Sporangia were then counted using a hemacytometer and expressed as sporangia per $\mathrm{cm}^{2}$ of infected peel surface.

Four experiments were conducted. Data were transformed to the $\log _{10}(x+1)$ and subjected to analysis of variance using the Mixed option in SAS Version 6.12. Wetness duration and temperature were treated

Table 1. Effect of temperature on sporangium formation in vitro by several isolates of Phytophthora palmivora

\begin{tabular}{|c|c|c|c|c|c|c|c|c|}
\hline \multirow[b]{2}{*}{ Temp $\left({ }^{\circ} \mathbf{C}\right)$} & \multicolumn{7}{|c|}{ Isolate } & \multirow[b]{2}{*}{ Avg. } \\
\hline & PIt B & Plt C & Frd 1 & Frd 2 & Sim & Sh-I & EB-1 & \\
\hline 17 & $0.77^{\mathrm{a}}$ & 0.43 & 0.74 & 0.88 & 0.70 & 0.58 & 0.15 & 0.61 \\
\hline 20 & 2.40 & 0.59 & 1.77 & 1.73 & 1.70 & 0.47 & 0.70 & 1.34 \\
\hline 24 & 7.46 & 8.77 & 4.81 & 5.71 & 6.97 & 1.92 & 2.58 & 5.46 \\
\hline 27 & 1.40 & 2.53 & 0.91 & 2.88 & 1.15 & 1.00 & 0.63 & 1.50 \\
\hline 30 & 0.51 & 0.35 & 0.23 & 0.17 & 0.79 & 0.33 & 0.30 & 0.38 \\
\hline 33 & 0.00 & 0.00 & 0.00 & 0.00 & 0.00 & 0.00 & 0.00 & 0.00 \\
\hline Avg. & 2.09 & 2.12 & 1.41 & 1.61 & 1.89 & 0.71 & 0.73 & \\
\hline Source & & & \multicolumn{2}{|c|}{$\mathrm{df}$} & \multicolumn{2}{|c|}{$F$} & \multicolumn{2}{|c|}{$P$} \\
\hline Isolate (I) & & & \multicolumn{2}{|c|}{6} & \multicolumn{2}{|c|}{2.63} & \multicolumn{2}{|c|}{0.0162} \\
\hline Temperature $(\mathrm{T})$ & & & \multirow{2}{*}{\multicolumn{2}{|c|}{$\begin{array}{r}5 \\
30\end{array}$}} & \multicolumn{2}{|c|}{71.36} & \multicolumn{2}{|c|}{0.0001} \\
\hline $\mathrm{I} \times \mathrm{T}$ & & & & & \multicolumn{2}{|c|}{1.04} & \multicolumn{2}{|c|}{0.4149} \\
\hline
\end{tabular}

${ }^{\mathrm{a}}$ Number of sporangia $\times 10^{4}$ formed after incubation in sterile distilled winter after $24 \mathrm{~h}$ at $27^{\circ} \mathrm{C}$. 
as fixed factors, and experiment was treated as a random factor. The experiments were analyzed as split plots, with temperature as the main plot and wetness duration as the subplot. Data from the four experiments were pooled, and an equation and graph that fit the data were generated using Table Curve 3D (SPSS, Inc., Chicago, IL).

Dispersal of sporangia. Sporangia of one isolate of $P$. nicotianae (BLTN) and three isolates of P. palmivora (Sh-I, Plt C, and Sim) were produced on brown rotaffected fruit as described above. One experiment was conducted with each isolate. Peel disks bearing sporangia were placed in the specimen chamber of a computercontrolled environmental chamber designed to monitor release and dispersal of airborne spores (6). Air flow was $1.0 \mathrm{~m} / \mathrm{s}$, which was designed to carry any sporangia released to the trapping surface without carrying water droplets bearing sporangia. Disks bearing sporangia were subjected to three 15 -min rain events at 15,60 , and 120 min after initiation of each experiment. Rain cycled on and off at 30-s intervals during the 15-min period, which allowed the chamber to drain and avoided flooding the specimen. The temperature was $23^{\circ} \mathrm{C}$, and $\mathrm{RH}$ was set at $50 \%$. RH increased to $100 \%$ during the rain events and declined to $50 \%$ again 10 to $15 \mathrm{~min}$ after each rain event.

Horizontal splash dispersal of sporangia was studied by placing 12-mm-diameter peel disks $2.1 \mathrm{~m}$ beneath the pipette used as the water droplet source. The peel disk was placed at the juncture of four $245 \times$ $245 \mathrm{~mm}$ Nunc bioassay plates containing PARPH (pimaricin-ampicillin-rifampicinpentachloronitrobenzene-hymexazol) selective medium $(16,21)$. The surface of the medium was $3 \mathrm{~cm}$ beneath the specimen surface. The number and distribution of the

Table 2. Effect of species of Phytophthora and isolate on sporangium production on the fruit surface

\begin{tabular}{|c|c|}
\hline Species isolate & $\begin{array}{l}\text { Sporangia/cm } / \mathrm{cm}^{2} \text { of } \\
\text { fruit surface } \times 10^{4}\end{array}$ \\
\hline \multicolumn{2}{|l|}{ P. palmivora } \\
\hline Plt C & $21.9 \pm 6.15^{\mathrm{a}}$ \\
\hline Sim & $14.3 \pm 6.71$ \\
\hline Sh-I & $12.6 \pm 6.34$ \\
\hline \multicolumn{2}{|l|}{ P. nicotianae } \\
\hline BLTN & $0.01 \pm 0.01$ \\
\hline BHG-7 & $0.03 \pm 0.01$ \\
\hline
\end{tabular}

${ }^{a}$ Mean \pm standard error of the mean.

Table 3. Analysis of variance of the effect of temperature and duration of fruit wetness on number of sporangia produced by Phytophthora palmivora, isolate Plt C

\begin{tabular}{lccc}
\hline Source & df & $\boldsymbol{F}$ & $\boldsymbol{P}$ \\
\hline Temperature $(\mathrm{Tp})$ & 3 & 35.25 & 0.0001 \\
Time $(\mathrm{Tm})$ & 4 & 79.85 & 0.0001 \\
$\mathrm{Tp} \times \mathrm{Tm}$ & 12 & 10.35 & 0.0001 \\
\hline
\end{tabular}

propagules dispersed after each of the first five droplets impacting the peel disks were studied by replacing the plates after each successive droplet. After exposure, plates were incubated for 3 days at $27^{\circ} \mathrm{C}$, and colonies were mapped on paper with $1-\mathrm{cm}$ concentric circles. The average number of colonies per $\mathrm{cm}^{2}$ was calculated for each concentric 1-cm-wide annulus surrounding the focus. Two experiments each were conducted with isolates BLTN and BHG-7 of $P$. nicotianae and isolates Plt C, EB-1, and Sh-I of $P$. palmivora. Four experiments were conducted with the Sim isolate of $P$. palmivora. The average droplet size was $0.065 \pm 0.010 \mathrm{ml}$.

The number of colonies versus distance was plotted for each of the droplets, one through five, for each isolate. The area under the curve (AUC) was calculated in each case. The effect of drop number on the number of propagules recovered was determined by analysis of variance using drop number as treatment and experiments
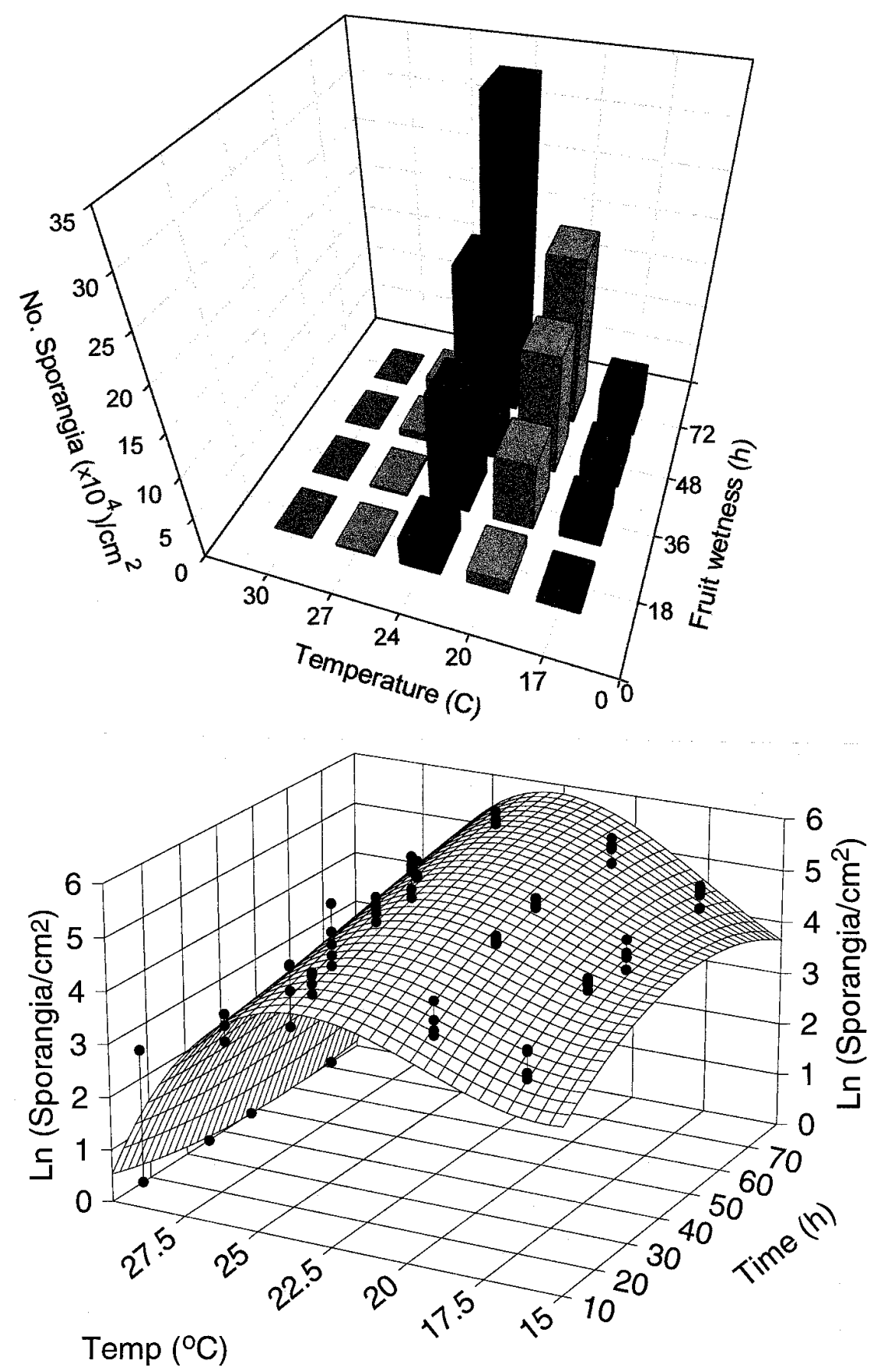

Fig. 2. Effect of temperature and duration of fruit wetness on sporangium production by Phytophthora palmivora: (top) bar graph of sporangium numbers, average of four experiments; (bottom) three-dimensional surface representation of the same data; $z=33.8-0.0017 x-5.169 y-0.0017 x^{2}+$ $0.2746 y^{2}+0.011 x y-0.00000052 x^{3}-0.0046 y^{3}-0.0004 x y^{2}+0.000068 x^{2} y ;\left(\mathrm{R}_{\mathrm{a}}^{2}=0.97\right)$, where $z=\ln$ (sporangia per $\left.\mathrm{cm}^{2}\right), x=$ temperature $\left({ }^{\circ} \mathrm{C}\right)$, and $y=$ duration of wetness $(\mathrm{h})$. 
and isolates as replicates. The effect of isolate on the recovery of propagules was determined by analysis of variance using experiments as blocks. Means were separated using LSD at $P \leq 0.05$.

Vertical and horizontal splash dispersal were evaluated for four isolates of $P$. palmivora (EB-1, Plt C, Sh-I, and Sim) and the BHG-7 isolate of $P$. nicotianae. Five plates $85 \mathrm{~mm}$ in diameter of PARPH medium were placed at each height in a straight line radiating out from a central peel disk bearing sporangia of the desired isolate. Each line of plates radiating out from the central disk like spokes of a wheel was arranged at heights of $-30,-15$, $0,15,45,60$, and $75 \mathrm{~mm}$ in reference to the height of the peel disk. In each experiment, a single drop of water was released to strike the peel disk. Plates were covered and incubated at $27^{\circ} \mathrm{C}$ for 3 days, and the colonies were counted. The average number of propagules in each distance category of 0 to 85,86 to 170,171 to 255,256 to 340 , and 341 to $425 \mathrm{~mm}$, and each height category, was calculated. Experiments were conducted at least twice with each isolate, and data presented are the means of all experiments conducted with each isolate.

\section{RESULTS}

Effect of temperature and duration of wetness on infection of fruit and development of brown rot. Duration of fruit wetness had little effect on disease incidence or lesion size. Analysis of variance of the first three experiments combined indicated that the effect of duration of wetness on infection was not a significant factor.

Because duration of wetness from 3 to $12 \mathrm{~h}$ was not an important factor in infection, the treatments with $6 \mathrm{~h}$ of wetness were used to evaluate temperature effects. Temperature was a highly significant factor $(P \leq 0.001)$ in the percentage of fruit infected and in the percentage of the fruit surface area affected. The optimum temperature range for infection was 27 to $30^{\circ} \mathrm{C}$, with considerably less infection at $24^{\circ} \mathrm{C}$ and none at $22^{\circ} \mathrm{C}$ or less (Fig. 1).

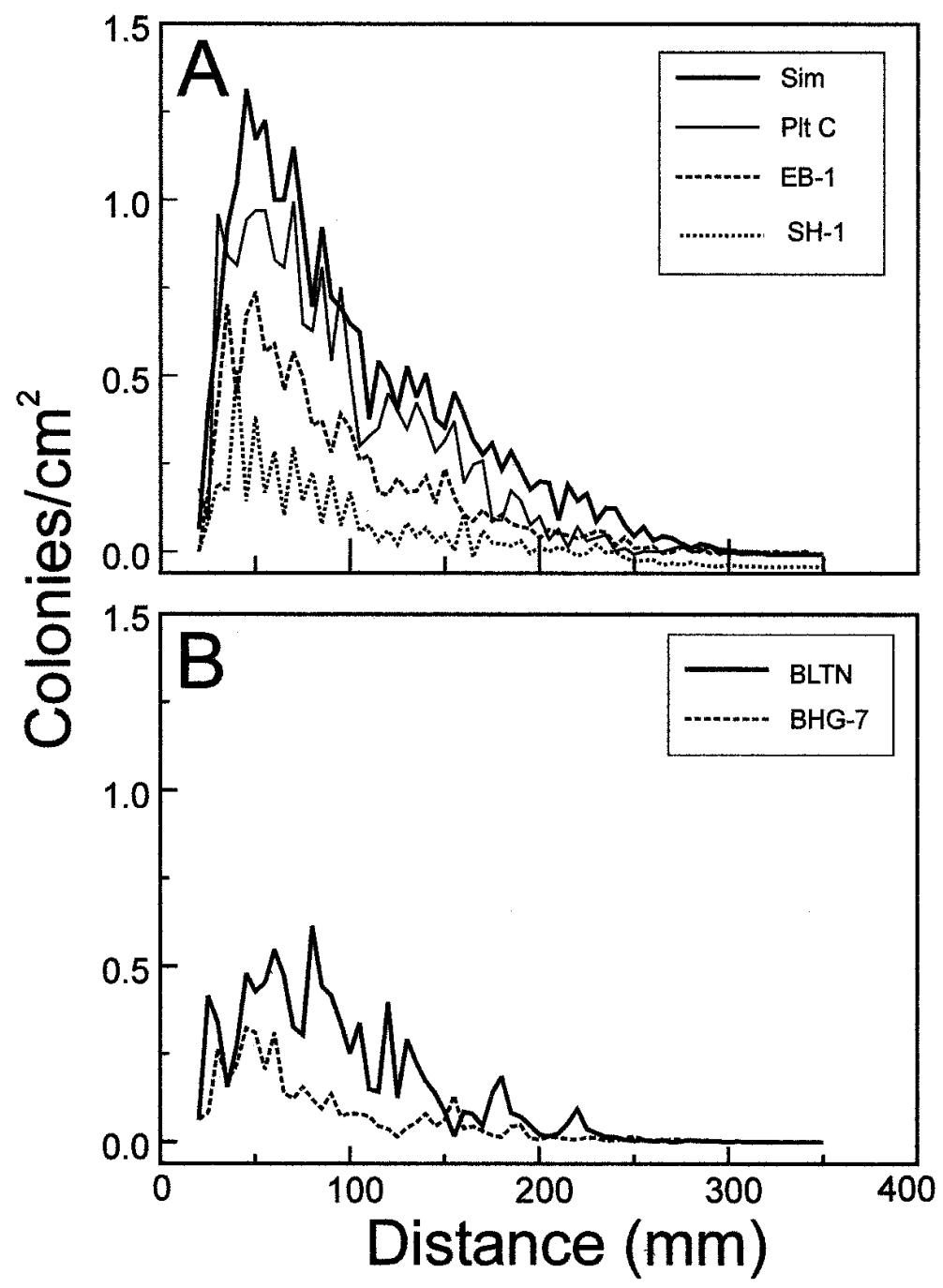

Fig. 3. Distance of horizontal splash dispersal of propagules of (A) Phytophthora palmivora (Sim, EB-1, Plt C, Sh-I) and (B) P. nicotianae (BLTN, BHG-7) by single water droplets falling on an infested disk of fruit peel.

Moderate infection occurred at $33^{\circ} \mathrm{C}$. The results with the percentage of the surface area affected were similar except that lesions were smaller at $30^{\circ} \mathrm{C}$ than at $27^{\circ} \mathrm{C}$.

Temperature and isolate effects on sporangium production in vitro. Temperature had a highly significant effect on production of sporangia (Table 1). The optimum temperature for sporangium production was $24^{\circ} \mathrm{C}$. As temperatures increased or declined from the optimum, sporangium production decreased sharply. No sporangia were produced at $33^{\circ} \mathrm{C}$.

Isolates differed significantly in their ability to produce sporangia. The greatest production was by isolates Plt B and Plt C, and the least was by isolates Sh-1 and EB1. There was no significant interaction between isolate and temperature (Table 1).

Sporangium production on fruit by isolates of $P$. palmivora and $P$. nicotianae. All three isolates of $P$. palmivora produced large numbers of sporangia on fruit, whereas two isolates of $P$. nicotianae produced almost no sporangia (Table 2). Highly significant differences in sporangium production occurred between the two species, but not among isolates within species.

Effects of temperature and fruit wetness duration on sporangium production by $P$. palmivora. Temperature and the duration of fruit wetness had highly significant effects on the production of sporangia by $P$. palmivora (Table 3 ). The interaction between duration and temperature was also highly significant.

Sporangium production was greatest at $24^{\circ} \mathrm{C}$ and decreased sharply at higher temperatures and somewhat less rapidly at lower temperatures (Fig. 2A). Sporangium production continued to increase with time of fruit wetness duration up to $72 \mathrm{~h}$, the longest period tested. The polynomial equation $z=33.8-0.0017 x-5.169 y-$ $0.0017 x^{2}+0.2746 y^{2}+0.011 x y-$ $0.00000052 x^{3}-0.0046 y^{3}-0.0046 y^{3}-$ $0.0004 x y^{2}+0.000068 x^{2} y$, where $z=\ln$ (sporangia per $\left.\mathrm{cm}^{2}\right), x=$ temperature $\left({ }^{\circ} \mathrm{C}\right.$ ), and $y=$ duration of wetness (h) provided a good fit for the data $\left(\mathrm{R}_{\mathrm{a}}{ }^{2}=0.97\right)$ (Fig. $\left.2 \mathrm{~B}\right)$.

Dispersal of sporangia. In experiments in the computer-controlled environmental chambers, no sporangia were trapped from the air following periods of simulated rain in any experiments with any of the three isolates of $P$. palmivora or with the $P$. nicotianae isolate.

In the experiments on horizontal splash dispersal, there was no significant effect of sequential drops on the colonies on the trap plates. As many propagules were recovered with the fifth drop impacting the target as with the first drop (data not shown).

There were some differences among isolates with regard to horizontal dispersal (Fig. 3). Isolates BHG-7 (P. nicotianae) and Sh-I (P. palmivora) had the lowest AUCs. These two isolates had significantly lower AUCs than the Plt C isolate of P. palmivora. 
Variability was high among and within experiments, and the AUCs of the other isolates were not significantly different.

In experiments on vertical and horizontal dispersal, single droplets were capable of splashing propagules of some isolates horizontally 350 to $425 \mathrm{~mm}$ (Fig. 4). Single droplets splashed propagules of some isolates to a height of 30 to $45 \mathrm{~mm}$, and up to $65 \mathrm{~mm}$ with isolate Plt C. Isolates Sh-I and Sim of $P$. palmivora were not dispersed as great a distance either vertically or horizontally as isolates EB-1 or Plt C. Propagules of BHG-7, an isolate of $P$. nicotianae, were only rarely recovered following the impact of single droplets.

\section{DISCUSSION}

Brown rot outbreaks occur sporadically in Florida citrus orchards. These epidemics generally follow extended periods of high rainfall $(2,9,20)$. However, no specific information existed on the duration of fruit wetness required for infection or sporangium production at various temperatures, and little information existed about dissemination of the pathogen.

Phytophthora spp. usually infect tissues rapidly at favorable temperatures. Gerlach et al. (5) found that $P$. citrophthora penetrated leaves of Pieris japonica in 2 to $4 \mathrm{~h}$ at favorable temperatures $\left(20\right.$ to $\left.30^{\circ} \mathrm{C}\right)$. With $P$. cactorum on strawberry fruit, Grove et al. (13) found that infection occurred in as little as $1 \mathrm{~h}$ at 17 to $25^{\circ} \mathrm{C}$. Grove and Boal (10) determined that the minimum wetness periods were about 3 to $4 \mathrm{~h}$ at 20 to $30^{\circ} \mathrm{C}$ for apple and pear fruit

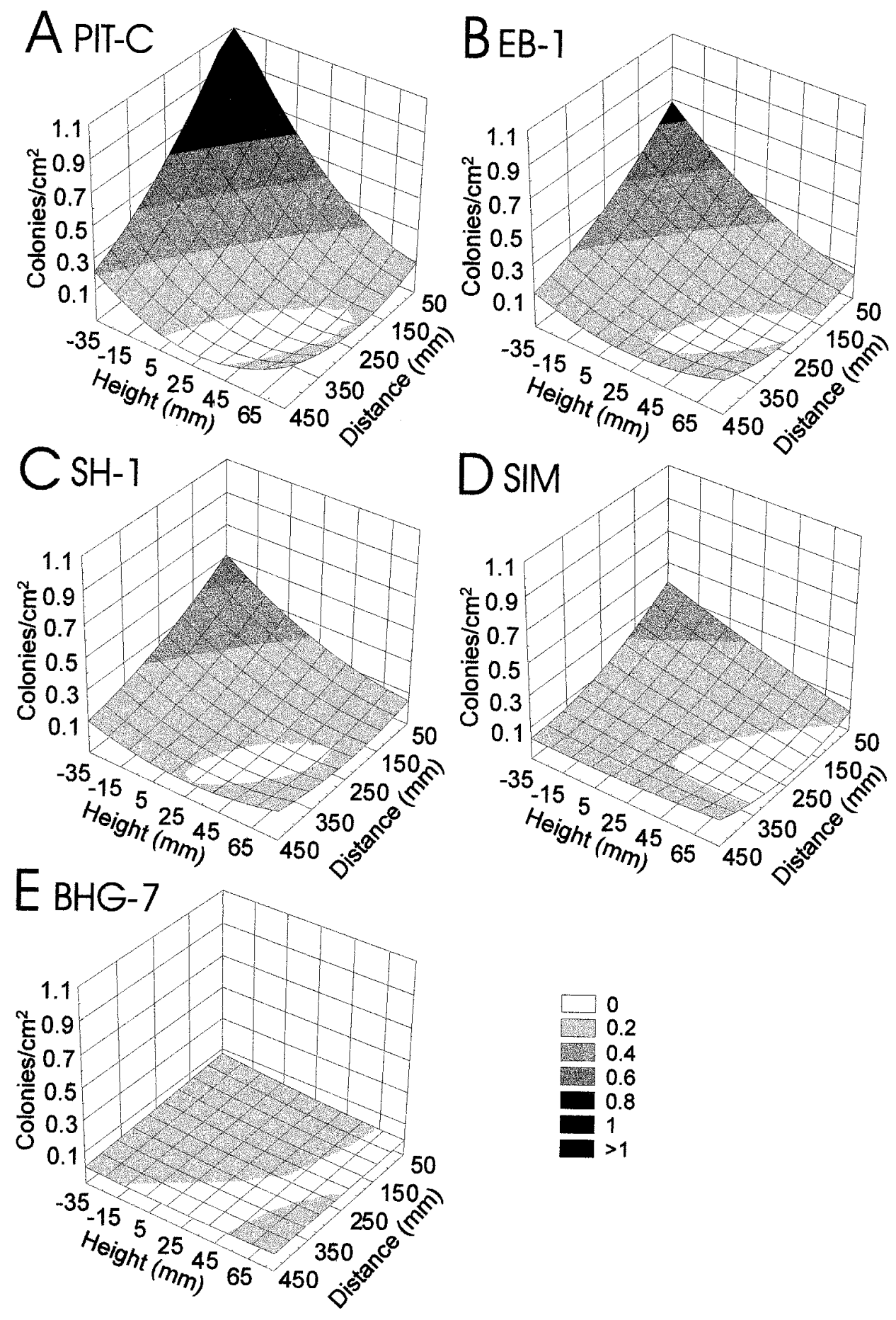

Fig. 4. Distance of horizontal and vertical splash dispersal of four isolates of Phytophthora palmivora, (A) Plt C, (B) EB-1, (C) Sh-I, and (D) SIM, and one isolate of $P$. nicotianae, (E) BHG-7, by single droplets of water on an infested disk of fruit peel. 
infected by $P$. cactorum. With citrus fruit, in the present study, infection reached a maximum with as little as $3 \mathrm{~h}$ of wetness duration. In Florida, leaf wetness durations exceed $3 \mathrm{~h}$ nearly every night and are often 10 to $12 \mathrm{~h}$. Thus, in brown rot epidemics, the length of wetness duration for infection would seldom be a limiting factor for epidemic development.

Temperature, however, could play a major role. $P$. palmivora is a high-temperature organism with an optimum for mycelial growth of $30^{\circ} \mathrm{C}$ (21). In this study, the optimum temperatures for infection and disease development were 27 to $30^{\circ} \mathrm{C}$. Surprisingly, brown rot caused by $P$. palmivora on citrus fruit did not develop at $22^{\circ} \mathrm{C}$ or below. Pieris japonica plants were infected by $P$. citrophthora at $12^{\circ} \mathrm{C}$, but infection required $15 \mathrm{~h}$ of leaf wetness (4). At $8^{\circ} \mathrm{C}$, no infection occurred. In the current study, infection occurred at lower temperatures. If fruit was inoculated at low temperature and inoculum droplets removed, no symptoms developed. However, if that fruit was moved to higher temperatures, symptoms developed. Storage of fruit at $5^{\circ} \mathrm{C}$ is recommended for postharvest control of brown rot (1). However, with brown rot caused by $P$. palmivora in Florida, simply cooling the fruit to 15 to $20^{\circ} \mathrm{C}$ should essentially halt disease development.

The optimum temperature for sporangium production by $P$. palmivora in vitro and on the fruit surface was $24^{\circ} \mathrm{C}$, which is considerably less than the optimum for growth in vitro (21) or for infection or disease development. Few sporangia were produced at high temperatures. At 27 to $30^{\circ} \mathrm{C}$, the diseased fruit commonly was colonized by yeast and bacteria, which may have interfered with sporangium formation. However, even in pure culture, sporangium production was low at those temperatures. All of the isolates tested were similar in this regard. In studies of $P$. citrophthora on Pieris japonica, the optimum temperatures for sporangium production and infection were similar (5).

In a previous study (9), we suggested that outbreaks occurring in earlier years $(2,19,20)$ were caused by $P$. palmivora rather than by $P$. citrophthora or $P$. nicotianae. Given that $P$. palmivora is such a high-temperature organism, it is difficult to explain previous winter outbreaks of the disease (2). However, rainfall in those cases extended over periods of several days. Temperatures ranging from 10 to $22^{\circ} \mathrm{C}$ certainly would have largely prevented disease development, but would not have precluded sporangium formation. Thus, sporangia formed during the rain on infected fruit were probably extensively dispersed by rain splash, and the lesions could develop during warmer periods following the rain. Winter temperatures in Florida seldom are lower than 10 to $12^{\circ} \mathrm{C}$ for more than 1 to 2 days.
Whiteside (20) attributed the restricted occurrence of brown rot in Florida to the limited distribution of $P$. palmivora (then designated as $P$. citrophthora). He found that $P$. nicotianae produced sporangia much more slowly than the other species in culture and on fruit peel disks in vitro. We have confirmed that observation on intact fruit.

Sporangium development on fruit at optimal temperatures is slow even for $P$. palmivora. Few sporangia are formed after $18 \mathrm{~h}$ of incubation, and numbers continue to increase up to $72 \mathrm{~h}$. With $P$. citrophthora on Pieris japonica, sporangial formation begins in 4 to $8 \mathrm{~h}$ and reaches a maximum at $24 \mathrm{~h} \mathrm{(5).} \mathrm{With} P$. cactorum on strawberry fruit, some sporangia were produced after $3 \mathrm{~h}$, and numbers increased with wetness periods up to $24 \mathrm{~h}$ (12).

Sporangia from $P$. palmivora from citrus are not dispersed by wind currents alone as are sporangia of $P$. infestans (4). Rather, like $P$. palmivora from papaya (14), they must be dispersed in droplets of water carrying sporangia. Single droplets of water were sufficient to dislodge the sporangia and carry them laterally up to distances of 350 to $450 \mathrm{~mm}$ and vertically at least 30 to $45 \mathrm{~mm}$. Up to five successive droplets continued to disperse similar amounts of inoculum. Rain droplets would be sufficient to propel small, sporangiumbearing droplets into the air, where they could be carried some distance by wind. As expected $(9,19), P$. nicotianae was not easily dispersed from infected fruit by falling droplets. Firstly, P. nicotianae produces far fewer sporangia than $P$. palmivora. Sporangia of $P$. nicotianae are also less caducous, and thus dispersal of $P$. palmivora occurs far more readily than spread of $P$. nicotianae. Our studies were carried out under different conditions than previous work on $P$. palmivora on papaya (14) or P. cactorum on strawberry (17), but our results appear to be consistent with those findings.

The scenario for development of brown rot epidemics that we have recently proposed (8) is supported by these results. $P$. palmivora apparently persists in soil in very low populations, and thus splash dispersal of soilborne propagules directly to low-hanging fruit does not occur readily. In contrast, $P$. nicotianae, which occurs in high populations in soil, infects fruit almost exclusively by this means. Little secondary spread occurs because few propagules are produced on the fruit surface. With $P$. palmivora, fruit that fall naturally or are dislodged by equipment in late summer or fall bait the fungus from the soil. This species then sporulates profusely on the fruit under moist conditions. Sporangia are then dispersed by rain splash. Epidemics occurred when temperatures were from 20 to $30^{\circ} \mathrm{C}$ and fruit wetness duration was greater than $12 \mathrm{~h}$ (8). These outbreaks are usually associated with sev- eral consecutive rain events and occur mostly from August to October, when fruit is beginning to mature and temperatures are still high. Winter outbreaks may occur, but extended periods of wet weather are needed when temperatures are low.

\section{ACKNOWLEDGMENTS}

The authors gratefully acknowledge the technical assistance of E. Canihos, P. M. Bushong, and A. M. Ibáñez. The advice of Ramon C. Littell (Department of Statistics, University of Florida) on analysis and presentation of the data is greatly appreciated. This research was funded in part by the Florida Citrus Production Research Advisory Council, Project 961-04.

\section{LITERATURE CITED}

1. Brown, G. E., and Eckert, J. W. 1988. Brown rot. Pages 32-33 in: Compendium of Citrus Diseases. J. D. Whiteside, S. M. Garnsey, and L. W. Timmer, eds. American Phytopathological Society, St. Paul, MN.

2. Cohen, M., and Knorr, L. C. 1960 . Winter outbreaks of citrus brown rot in Florida. Plant Dis. Rep. 44:578-579.

3. Doo, S. Y. A. C. 1964. The influence of temperature and inoculum level on disease development in Carica papaya L. caused by Phytophthora palmivora Dast. M.S. thesis University of Hawaii, Honolulu.

4. Erwin, D. C., and Ribeiro, O. K. 1996. Phytophthora Diseases Worldwide. American Phytopathological Society, St. Paul, MN.

5. Gerlach, W. W. P., Hoitink, H. A. J., and Schmitthenner, A. F. 1976. Phytophthora citrophthora on Pieris japonica: Infection, sporulation, and dissemination. Phytopathology 66:302-308.

6. Gottwald, T. R., Trocine, T. M., and Timmer, L. W. 1997. A computer-controlled environmental chamber for the study of aerial fungal spore release. Phytopathology 87:1078-1084.

7. Graham, J. H., and Timmer, L. W. 1992 Phytophthora diseases of citrus. Pages 250 269 in: Plant Diseases of International Importance. Vol. III. Diseases of Fruit Crops. J. Kumar, H. S. Chaube, U. S. Singh, and A. N. Mukhopadhyay, eds. Prentice-Hall, Englewood Cliffs, NJ.

8. Graham, J. H., and Timmer, L. W. 1998. Citrus brown rot: Status and control. Citrus Ind. 79(7):15-17.

9. Graham, J. H., Timmer, L. W., Drouillard, D. L., and Peever, T. L. 1998. Characterization of Phytophthora spp. causing outbreaks of citrus brown rot in Florida. Phytopathology 88:724729.

10. Grove, G. G., and Boal, R. J. 1991. Influence of temperature and wetness duration on infection of immature apple and pear fruit by Phytophthora cactorum. Phytopathology 81:1465-1471.

11. Grove, G. G., Madden, L. V., and Ellis, M. A. 1985. Splash dispersal of Phytophthora cactorum from infected strawberry fruit. Phytopathology 75:611-615.

12. Grove, G. G., Madden, L. V., and Ellis, M. A. 1985. Influence of temperature and wetness duration on sporulation of Phytophthora cactorum on infected strawberry fruit. Phytopathology 75:700-703.

13. Grove, G. G., Madden, L. V., Ellis, M. A., and Schmitthenner, A. F. 1985. Influence of temperature and wetness duration on infection of immature strawberry fruit by Phytophthora cactorum. Phytopathology 75:165-169.

14. Hunter, J. E., and Kunimoto, R. K. 1974. Dispersal of Phytophthora palmivora by wind-blown rain. Phytopathology 64:202206. 
15. Knorr, L. C. 1956. Progress of citrus brown rot in Florida, a disease of recent occurrence in the state. Plant Dis. Rep. 40:722-774.

16. Mitchell, D. M., Kannwischer-Mitchell, M. E., and Zentmyer, G. A. 1986. Isolating, identifying, and producing inoculum of Phytophthora spp. Pages 63-66 in: Methods for Evaluating Pesticides for Control of Plant Pathogens. K. D. Hickey, ed. American Phytopathological Society, St. Paul, MN.
17. Reynolds, K. M., Madden, L. V., Reichard, D. L., and Ellis, M. A. 1989. Splash dispersal of Phytophthora cactorum from infected strawberry fruit by simulated canopy drip. Phytopathology 79:425-432.

18. Timmer, L. W., Sandler, H. A., Graham, J. H., and Zitko, S. E. 1988. Sampling citrus orchards in Florida to estimate populations of Phytophthora parasitica. Phytopathology 78:940-944.
19. West, E., Cohen, M., and Knorr, L. C. 1954. Brown rot of citrus on the tree in Florida. Plant Dis. Rep. 38:120-121.

20. Whiteside, J. O. 1970. Factors contributing to the restricted occurrence of citrus brown rot in Florida. Plant Dis. Rep. 54:608-611.

21. Zitko, S. E., Timmer, L. W., and Sandler, H. A. 1991. Isolation of Phytophthora palmivora pathogenic to citrus in Florida. Plant Dis. 75:532-535. 